Patrique Segers

Bas A. de Mol

\title{
Prevention of ventilator-associated pneumonia after cardiac surgery: prepare and defend!
}

Received: 16 April 2009

Accepted: 17 April 2009

Published online: 26 June 2009

(C) The Author(s) 2009. This article is published with open access at Springerlink.com

This editorial refers to the article available at: doi:10.1007/s00134-009-1523-3.

P. Segers $(\varpi) \cdot$ B. A. de Mol

Departments of Cardiothoracic Surgery,

Academic Medical Center, University of Amsterdam,

Meibergdreef 9, 1105 AZ Amsterdam, The Netherlands

e-mail: p.segers@amc.uva.nl

To expect that all patients undergoing major surgery can have unflawed outcomes is not realistic. Surgery is performed by humans on humans and always will have complications such as nosocomial infections. Despite the progress in surgery and anaesthesia, the risk of developing nosocomial infections remains a real threat as more patients of greater age and with more co-morbidity are to be operated on [1].

Ventilator-associated pneumonia (VAP) is the most frequent intensive care unit (ICU) acquired infection among patients receiving mechanical ventilation (MV) $[2,3]$. Analysis of the impact of VAP on health care revealed it to be responsible for a significant increase in mortality, morbidity, and lengths of MV and ICU stay [3-7]. Needless to say, prevention of VAP is essential.

This issue of Intensive Care Medicine contains a report by Hortal et al. of a prospective study conducted to identify potentially modifiable risk factors for VAP in patients undergoing cardiac surgery amenable for intervention [8]. As a secondary objective they tried to derive an easy-to-calculate risk score from their multivariate analysis. They found a cumulative incidence of VAP of $5.7 \%$. In the sub-group of patients needing MV longer than $48 \mathrm{~h}$ VAP incidence was $45.9 \%$. Overall, the main pathogens causing VAP were Enterobacteriaceae (32.8\%), Pseudomonas aeruginosa (28.6\%), and Staphylococcus aureus (27.1\%). Importantly, $65.8 \%$ of these S. aureus infections were MRSA. Obviously patients with VAP had a longer ICU stay (25.5 days vs. 3 days). Overall in-hospital mortality in the study population was $6.9 \%$. However, 90 patients were excluded as a result of intra-operative or early post-operative $(48 \mathrm{~h})$ death, leading to an overall mortality of $11.2 \%$.

Risk factors found were: age $>70$, blood transfusion, days of MV, cardiopulmonary bypass time, reintubation, emergent surgery, intraoperative inotropic support, and previous cardiac surgery.

The colonization of the host by potentially pathogenic micro-organisms is a prerequisite for the development of nosocomial infections. Whether an infection develops is the result of the dynamic interactions that take place between a host, a potential pathogen, and the environment. It occurs when host defense strategies are successfully evaded by micro-organisms and results in deleterious changes in the host. Multiple risk factors contribute to microbial pathogenicity. Hortal et al. suggest that most risk factors are not amenable to intervention. The risk factors found are not surprising in a surgical population at higher risk of developing infections because patients are older and with more comorbidity. But what can, or must, be done to prevent the development of VAP (in patients undergoing cardiac surgery)? Excellent surgical technique still remains one of the most important factors in the prevention of nosocomial infections. For instance, inadequate hemostasis can lead to hypovolemia resulting in an increased need for blood transfusion, inotropic support, duration of surgery, or even possible re-operation [9]. But first, prevention should be focused on optimizing host defenses. 
Preoperative assessment of patients undergoing cardiac surgery should be regarded as an opportunity to reduce nosocomial infection risk and improve the patient's general health. In patients undergoing CABG surgery a preoperative inspiratory muscle-training program reduced the incidence of pneumonia by $13 \%$ [10]. After surgery, malnutrition is associated with increased mortality, increased length of hospital stay, and postoperative complications, including increased risk of infection [10]. Early recognition of malnourished patients is essential for prevention of postoperative complications. Careful preoperative nutritional assessment is therefore important in order to make an early diagnosis $[11,12]$. This can be performed by a validated, easy-to-use hospital screening tool such as the short nutritional assessment questionnaire (SNAQ) [12]. Experimental studies have shown that nutritional support containing L-arginine, omega-3 polyunsaturated fatty acids, and nucleotides improves preoperative host defenses and subsequently reduces postoperative infections. So far only one level I trial has suggested that intake of immune-enhancing nutritional supplement for a minimum of five days preoperatively can improve outcome in high-risk patients undergoing elective cardiac surgery [13].

Thereafter, the microbiological burden should be controlled. The pathogenesis of pneumonia, including VAP, involves aspiration of bacteria from the oropharynx into the lung, especially during MV. Several systematic reviews and guidelines now available have made recommendations including: try to minimize the duration of intubations as much as possible, for instance by implementing weaning protocols or interrupted sedation schedules; try to avoid reintubation, for instance by noninvasive-ventilation; try to avoid a supine patient position, especially when a patient receives enteral feeding; use closed ventilator circuits; try to reduce aspiration of oropharyngeal secretions, for instance by continuous aspiration of subglottic secretions; and minimize the risk of cross-transmission of pathogens in the ICU by enforcing optimal hand hygiene and maintaining adequate staffing levels [4, 14-17].

Several studies have identified the pivotal role of oropharyngeal colonization in the pathogenesis of VAP. Reductions in the incidence of VAP have been achieved by use of prophylactic antibiotic regimens given intravenously, given topically in the oropharynx, or given as part of selective decontamination of the digestive tract (SDD) or selective oropharyngeal decontamination (SOD). A recent trial comparing SDD and SOD found similar effects on survival [18]. Therefore, the SOD regimen seems preferable to the SDD regimen because it does not include widespread systemic prophylaxis with cephalosporins and involves a lower volume of topical antibiotics, thus minimizing the risk of selection for and development of antibiotic resistance in the long term. Selection of antibiotic resistance remains the major disadvantage of these strategies, however, limiting its applicability in settings with high levels of antibiotic resistance including settings in which Hortal et al. performed their study [19, 20]. MRSA was found in almost $50 \%$ of all S. aureus infections. Therefore, oropharyngeal decontamination with antiseptic agents, for example chlorhexidine gluconate ( $\mathrm{CHX})$, seems to be an important alternative. This is an inexpensive and effective solution and is virtually devoid of adverse effects. Results from longterm clinical studies have indicated no adverse alterations in microbial resistance. Two recent trials found important absolute risk reductions of VAP (6.5 and 8\%) in patients treated with CHX [21,22].

To identify a population at high-risk of pneumonia Hortal et al. try to develop a "day-zero score" with the variables available before surgery. In this way high-risk patients can be identified and targeted preventive measures can be started in a cost-effective manner. The score would accurately identify $93 \%$ of patients who will develop pneumonia, with a specificity of $40 \%$. The score is of limited use because it is based on a small numbers of patients. The authors state that further studies, especially with a large sample size, are needed to validate this score. A "day-3 score" was developed to identify patients at higher risk of developing pneumonia among those who remained ventilated for more than $48 \mathrm{~h}$. These patients could be candidates for antimicrobial preventive measures. The only risk factor found was age $>70$ years. As high levels of antibiotic-resistant bacteria were found, antimicrobial preventive measures like SDD or SOD should, obviously, not be used. In this setting, CHX seems to be an important alternative $[21,22]$. But as this method is easy-to-use, inexpensive, and with virtually no adverse effects, it can be used in all patients undergoing cardiac surgery.

vVAP still remains a frequent ICU-acquired infection responsible for a significant increase in morbidity and mortality. Hortal et al. define a number of risk factors and give a start by suggesting a risk score for medical decision-making on duration of intensive care and mechanical ventilation. In contrast with the suggestion of Hortal et al., we take the position that risk factors are amenable to intervention. For patients undergoing major surgery the situation is similar to that in sportswinning begins with optimal preparation followed by a good defense.

Open Access This article is distributed under the terms of the Creative Commons Attribution Noncommercial License which permits any noncommercial use, distribution, and reproduction in any medium, provided the original author(s) and source are credited. 


\section{References}

1. The Society of Thoracic Surgeons National Database. http://www.sts.org/section/stsdatabase/

2. Vincent JL, Bihari DJ, Suter PM (1995) The prevalence of nosocomial infection in intensive care units in Europe. Results of the European Prevalence of Infection in Intensive Care (EPIC) Study. EPIC International Advisory Committee. JAMA 274:639-644

3. Rello J, Ollendorf DA, Oster G (2002) Epidemiology and outcomes of ventilator-associated pneumonia in a large US database. Chest 122:2115-2121

4. Arabi Y, Al-Shirawi N, Memish Z (2008) Ventilator-associated pneumonia in adults in developing countries: a systematic review. Int J Infect Dis 12:505-512

5. Kluytmans JA, Mouton JW, Maat AP, Manders MA, Michel MF, Wagenvoort JH (1994) Surveillance of postoperative infections in thoracic surgery. J Hosp Infect 27:139-147

6. Kollef MH, Sharpless L, Vlasnik J, Pasque C, Murphy D, Fraser VJ (1997) The impact of nosocomial infections on patient outcomes following cardiac surgery. Chest 112:666-675

7. Anonymous (2004) National nosocomial infections surveillance (NNIS) system report, data summary from January 1992 through June 2004, issued October 2004. Am J Infect Control 32:470-485

8. Hortal J, Giannella M, Perez MJ, Barrio JM, Desco M, Bouza E, Muñoz P (2009) Incidence and risk factors for Ventilator Associated Pneumonia after Major Heart Surgery. Intensive Care Medicine

9. Levy JH, Tanaka Kasteiner ME (2005) Evaluation and management of bleeding during cardiac surgery. Curr Hematol Rep 4:368-372
10. Hulzebos EHJ, Helders PJM, Favié NJ (2006) Preoperative intensive inspiratory muscle training to prevent postoperative pulmonary complications in high-risk patients undergoing CABG surgery: a randomized clinical trial. JAMA 296:1851-1857

11. Gianotti L (2006) Nutrition and infections. Surg Infect 7:S29-S32

12. Kondrup J, Rasmussen HH, Hamberg $\mathrm{O}$, Stanga Z, Hoc Espen Working Group (2003) Nutritional risk screening (NRS 2002): a new method based on analysis of controlled clinical trials. Clin Nutr 22:321-336

13. Kruizenga HM, van Tulder MW, Seidell JC, Ader HJ, Bokhorst-de Van, van der Schueren MAE (2005)

Effectiveness and cost-effectiveness of early screening and treatment of malnourished patients. Am J Clin Nutr 82:1082-1089

14. Tepaske R, te Velthuis H, Oudemansvan Straaten HM, Heisterkamp SH, van Deventer SJH, Ince C, Eijsman L, Kesecioglu J (2001) Effect of preoperative oral immune-enhancing nutritional supplement on patients at high risk of infection after cardiac surgery: a randomized placebocontrolled trial. Lancet 358:696-701

15. Tablan OC, Anderson LJ, Besser R, Bridges C, Hajjeh R (2004) CDC. Guidelines for preventing health-careassociated pneumonia, 2003. Recommendations of the CDC and the healthcare infection control practices advisory committee. MMWR 53 (No. $\mathrm{RR}-3$ )

16. Shorr AF, Kollef MH (2005) Ventilator-associated pneumonia: insights from recent clinical trials. Chest 128:583S-591S
17. Bouza E, Pérez MJ, Muñoz P, Rincón C, Barrio JM, Hortal J (2008) Continuous aspiration of subglottic secretions in the prevention of ventilator-associated pneumonia in the postoperative period of major heart surgery. Chest 134:898-900

18. de Smet AM, Kluytmans JA, Cooper BS, Mascini EM, Benus RF, van der Werf TS, van der Hoeven JG, Pickkers $\mathrm{P}$, Bogaers-Hofman D, van der Meer NJ (2009) Decontamination of the digestive tract and oropharynx in ICU patients. N Engl J Med 360:20-31

19. Kollef MH (2003) Selective digestive decontamination should not be routinely employed. Chest 123:464S468S

20. Bonten MJ (2006) Selective digestive tract decontamination-will it prevent infection with multidrug-resistant Gram-negative pathogens but still be applicable in institutions where methicillin-resistant Staphylococcus aureus and vancomycin-resistant enterococci are endemic? Clin Infect Dis 43:S70-S74

21. Segers $P$, Speekenbrink RGH, Ubbink DT, van Ogtrop ML, de Mol BA (2006) Prevention of nosocomial infection in cardiac surgery by decontamination of the nasopharynx and oropharynx with chlorhexidine gluconate. A randomized controlled trial. JAMA 296:2460-2466

22. Koeman M, van der Ven AJ, Hak E, Joore HC, Kaasjager K, de Smet AG, Ramsay G, Dormans TP, Aarts LP, de Bel EE (2006) Oral decontamination with chlorhexidine reduces the incidence of ventilator-associated pneumonia. Am J Respir Crit Care Med 173:1348-1355 